\title{
Investigating Non-formal EFL Teachers' Wellbeing in an English Course in Yogyakarta, Indonesia
}

\author{
Anita Galuh Sri Hapsari \\ Sanata Dharma University, Indonesia \\ Email: anitagaluhs@gmail.com
}

\begin{abstract}
Teachers' wellbeing potentially carries domino effects on their performances in class. Teachers develop their creativity to perform teaching and learning activities in class when they achieve wellbeing. It affects the students whether they enjoy their learning process with the teachers. This qualitative study aims to explore how the nonformal English teachers experience teaching, working dynamics and complexities from teachers' points of view; and how these subject matters affect their wellbeing. In-depth interviews were conducted to obtain the data from the research participants. The data were analyzed by employing Holmes's (2005) categories of teachers' wellbeing. The findings and discussion of this research demonstrates that the teachers achieved intellectual, emotional, and spiritual wellbeing through different trajectories. The result of this study contributes to English courses as companies to maintain the teachers' wellbeing for the sake of teachers' performances. Future researchers are suggested to conduct similar study with quantitative approach in order to get bigger and general picture of nonformal EFL teacher wellbeing.
\end{abstract}

Keywords: EFL teachers, English course, non-formal EFL teachers, teachers' wellbeing

\section{INTRODUCTION}

According to Cambridge Advanced Learners' Dictionary, wellbeing is defined as the state of feeling happy and healthy. This positive emotional state is considered as the result of the harmony of personal needs, contextual factors, and expectations towards working environments (Engels, Aelterman, Petegem, \& Schepens, 2004). In the school context, teachers should be able to sustain the positive emotional state by maintaining the harmony among the three subject matters. Being capable of adjusting their personal needs, expectations to specific contexts, and school demands is highly needed by teachers if they intend to maintain their wellbeing. It is essential that teachers fit into the school system (van Petegem, Creemers, Rossel, \& Aelterman, 2005) in order to reach the harmony that triggers wellbeing.

Holmes (2005) divides wellbeing into four sub-categories, namely physical wellbeing, emotional wellbeing, mental and intellectual wellbeing, and spiritual wellbeing. Physical wellbeing refers to the state of health in the sense of balancing mind and body. In the school context teachers' physical wellbeing is associated to the capability of teachers in maintaining their health while coping with school work responsibilities effectively. Emotional wellbeing refers to the ability to recognize, understand, and express emotions ap- propriately. Emotional wellbeing includes skills to handle one's own emotion, to stay motivated, and to be able to emphatically understand others' emotions (Goleman, 1995). Mental and intellectual wellbeing refers to the state of emotion in which teachers feel improving in the workplace. The mindset of willingness to develop as teachers at school influences mental and intellectual wellbeing. Spiritual wellbeing serves as the source of inspiration helping teachers "to live and work with integrity, compassion, connection, enthusiasm, meaning and vision" (Holmes, 2005: p.11).

The recent studies have explored about the relation between teachers' wellbeing, burnout, and the effect on their professional development. Several numbers of researchers have explored the wellbeing of teachers in schools. Cumming (2016) claimed four possible aspects influencing teachers' wellbeing, namely work environment, workplace relationships, job satisfaction, and psychological and emotional well-being. Good and comfortable work environments and supportive colleague relationships had great association with higher job satisfaction (Schreyer \& Krause, 2016) leading to wellbeing. Teachers' job satisfaction is influenced by management support, teacher autonomy, relations with colleagues, nature of work, and working conditions. The study conducted by Veldman, van Tartwijk, Brekelmans, \& Wubbels (2013) among Dutch teachers 
found that there was a positive relation between teachers' job satisfaction and the teacher-student relationship at the beginning until the end of their career.

The research by Cassidy et al. (2016) on early childhood teachers' wellbeing in California found that teachers' autonomy in their workplace and teachers' perception of their salary fairness had correlation to teachers' classroom emotional support. In addition, teachers' wages as a part of wellbeing were connected to children's positive emotional expressions and behaviors in classrooms. In the Australian setting, Bower \& Carroll (2017) developed web-based application to conduct research on teachers' wellbeing focusing on emotional regulation. The result showed that student behavior and teachers' amount of work triggered negative emotional states while staffroom generated positive effect on teachers' real-time emotional states. Students' parents and collegial relationship among teachers could also be the factor influencing teachers' emotional conditions. Faulkner, Gerstenblatt, Lee, Vallejo, \& Travis (2016) found that teachers' interactions with students' parents became the greatest source of workplace pressure, whereas Nislin et al. (2016) claimed that teachers' well-being was most frequently affected by the quality of relationships with their coworkers. In addition, good quality of collegial relationship stimulated positive interaction, atmosphere, and bond in the workplace (Retallick \& Butt, 2004).

Even though a number of researchers have been conducted studies about teacher wellbeing, there has not been a study investigating English teacher wellbeing in the context of non-formal education. The previous research has not explored about other context of EFL teaching and learning, particularly in non-formal education context yet. To fill this gap, this current study is aimed at investigating EFL teachers' wellbeing working at non-formal educational institution. As this research setting is in Indonesian context, it is needed to review about educational streams in Indonesia. The review gives pictures for foreign readers who potentially have different understanding in educational streams due to the educational system in their countries.

There are three streams of education in Indonesia, namely formal, non-formal, and informal education (Center for Educational Assessment, 2015). These educational streams can complete and enrich each other through faceto-face interaction in classroom and/or may be supplemented or replaced with virtual classes. The formal education includes basic, seconda- ry, and higher education levels with variety of educational types, namely general, vocational, professional, religious, and special education. Meanwhile, non-formal education can be functioned as replacement (such as homeschooling), complement (such as institutional study guidance focusing on helping students with school lesson mastery), and supplementary (such as language course for academic, general, and specific purpose). The aim of non-formal education is to accelerate students' knowledge and skill acquisition in addition to sharpening personality and professionalism. The types of non-formal education in Indonesia consist of life skill development, early childhood and youth education, woman empowerment, literacy education, vocational training, student ability development, and equivalency program. All educational streams, levels, and types are administered by either national government (Peraturan Pemerintah tentang Standar Nasional Pendidikan, 2005), local government, communities, non-governmental organizations, and/or any permutation thereof.

In this study, non-formal education refers to the English course as supplementary education concentrating on English mastery development. It is registered and accredited by Department of Non-formal Education under the Ministry of Indonesian Education and Culture. This English course is located in Yogyakarta Province, Indonesia. This non-formal educational institution has two branches located in different districts.

Teachers in this English course are all females and have responsibilities to do set of tasks, namely preparing teaching materials, attending weekly meeting, and doing administrative tasks (bridging the course and students' parents, writing weekly class report, and writing progress report). In the first years teachers need to accomplish all levels of development training. The teachers also need to perform in front of their peers and supervisors in weekly upgrading meeting by conducting micro teaching to get some feedback. Besides, when the accreditation time from the government comes, all staff and teachers have to deal with the requirements, especially a load of accreditation documents.

This research aims to explore how the non-formal English teachers experience teaching, working dynamics and complexities from teachers' points of view; and how these subject matters affect their wellbeing. The result of this research will give contribution to literature on non-formal education teachers' wellbeing; it can also be a reference for non-formal education institutions, particularly language courses to maintain their te- 
achers' wellbeing. Course administrators can also take benefits from this research. They can gain information on working dynamics that the teachers experience and make it as the base of internal evaluation for their better educational institution. To conduct this study, the researcher formulated a research question to investigate, that is: What kinds of wellbeing are revealed from the nonformal English teachers in the English course? To answer the research question, the methodology was employed and explained as follows.

\section{METHODOLOGY}

This qualitative study aimed to bring rich descriptive explanation (Ary, Jacobs, \& Sorensen, 2010) to figure out non-formal English teachers' wellbeing in an English course in Yogyakarta. In this qualitative study the researcher became the human instrument who collected the data (Creswell, 2012). This study sited non-formal English teachers' wellbeing within each teacher's professional trajectory. By interpreting the teachers' retrospective professional experiences in non-formal English education, the researcher explored how the six participants enacted their wellbeing in professional development.

\section{Research Setting and Participants}

This study was conducted at an accredited English course in Yogyakarta. The participants of this study were six English teachers in the non-formal English course with various lengths of working experiences and job positions from both branches of the English course. Two junior teachers were voluntary invited to share their experience regarding this inquiry. They had just passed the first two-year of contract which was often considered as the honeymoon phase in which they experienced happiness and satisfaction of having a new job and as the most difficult period that might present them with strong contextual challenges (Fantilli \& McDougall, 2009). The other four senior teachers were also invited to share their experiences; two of them had been working for around ten years and positioned as English division managers while the other two were ordinary teachers with more than seven years of working experiences and twelve years of working experiences respectively. Senior teachers had passed years of their development training and experienced more dynamics happened in the course during their career. These participants retrospectively shared changes, challenges, and improvements they had been feeling throughout the years of working. Table 1 presented the description of the participants involved in this research.

\section{Data Collection}

Before conducting the research, the researcher asked for permission from the owner director of the institution. The researcher and the owner director had understood each other and agreed that any results of this study would bring no harm for the English course. During the meeting with the owner director, the researcher also conducted unpremeditated impromptu interview. The researcher gained information about the institution, including accreditation, semester events, education philosophy, and the vision and mission of the institution from the casual talk. Note-taking was done in order to record important points related to the present inquiry as the permission was obtained.

Before the interview, the researcher met the participants in group at lunch time. The researcher, then, explained the participants about the research and asked whether the participants were intended to take part in the study. As they stated their voluntary intention to be the participants, the researcher and participants made appointment to have further discussion and in-

Table 1. Research participants

\begin{tabular}{lll}
\hline $\begin{array}{l}\text { Participants' Years of } \\
\text { Working }\end{array}$ & Position & Working Hours \\
\hline $\begin{array}{l}\text { Participant 1:2 years } \\
\text { Participant 2: 2 years }\end{array}$ & class advisor and English teacher & \\
Participant 3: 7 years & & \\
Participant 4: 10 years & class advisor, English teacher and division manager & 42 hours per week \\
Participant 5: 10 years & & \\
Participant 6: 12 years & $\begin{array}{l}\text { Branch B, class advisor, English teacher, and assis- } \\
\text { tant of branch manager (assisting the BM to handle } \\
\text { mathematics courses) }\end{array}$ \\
\hline
\end{tabular}


terview regarding the current inquiry out of the office hours.

When the time and place for the real interview agreed by each participant, individual life-history interview was conducted in order to obtain detailed information of the participants' wellbeing. The researcher explained the research inquiry. After the explanation, the participants signed consent form was done before the interview which lasted around 30-45 minutes for each participant. The interview was conducted in casual Indonesian-English to avoid any language barriers, audio-recorded and transcribed. After all individual life-history interview transcribed, the researcher read and reread the transcript to familiarize with the data and took some notes to give initial label of the utterances. Member check was conducted by distributing each of the transcripts to the interviewees through email or an application-based short message attachment. When it was possible, the researcher and participants sat together to review the accuracy and meaning of the utterances transcribed. Notion clarification by the participants was welcomed if different points of information occurred. Due to the participants' time limitation, not all participants were available to meet and sit together. Some participants did the member check through email.

\section{Data Analysis}

The transcripts were analyzed after the entire data checking was done. The researcher reread and organized them into unit of meaning based on the Activity Theory framework (Engeström, 1999; Engeström, Miettinen, \& Punamäki, 1999), namely subject (the non-formal English teachers), instrument (classroom facilities, curriculum, relationships), object (achievement of wellbeing), rule (the course rules governing the teachers), community (the English course), and division of labor (the position of teachers to do academic and non-academic tasks). This framework shed light on how the teachers' wellbeing was constructed in their situated activity systems including factors that influenced it.

Holmes (2005) theoretical framework of teachers' wellbeing was employed to support the discussion and presentation of the data in more specific themes related to teachers' wellbeing, namely physical wellbeing, emotional wellbeing, mental and intellectual wellbeing, and spiritual wellbeing. To ensure the validity of data analysis, the third person who had no relation with the research participants and institution was invited as the second coder to conduct data analysis by describing and marking the data based on the same approach as the researcher did. The researcher and the second coder shared and compared the results of their data analysis, discussed it and made agreement when different labels of groupings happened.

\section{FINDINGS AND DISCUSSION}

The non-formal English teachers faced working dynamics in their workplace in which they were also governed with rules. Moreover, the teachers were assigned tasks based on their division of labor, such as doing academic and non-academic tasks. In this English course, teachers were also responsible to deal with promotion events. They conducted education fair in public places, such as at schools and malls. The promotion event in malls was packed as one-day event that make them spend their whole weekend for this event. However, they were able to deal with challenges as saw their responsibilities as experiences, dynamics, and complexities they faced in their professional development.

Beside the aspects of rule, community, and division of labor, tools or instruments of the contextual framework, namely classroom facility, curriculum, and relationship, also played important role in supporting the teachers in achieving their wellbeing. The teachers stated that all course books and syllabi had been made by the course authority. Moreover, classroom facilities to conduct the learning had also been prepared and ready to use. In this case, the teachers had already got the guideline of what they were expected to teach. Therefore, they could concentrate more on the teaching techniques without getting busy to make the materials of teaching themselves.

Relationship, as a part of the instrument to achieve wellbeing, became an important trajectory for teachers to achieve their wellbeing. This finding was in line with Nislin et al. (2016) who claimed that teachers' well-being was elicited by the quality of relationships with their peers. Moreover, collegial bond stimulated positive collaboration, situation, and connection in the workplace (Retallick \& Butt, 2004).

From the analysis of the Activity Theory, it was clearly seen that complexities of aspects contributed to the teachers' achievement of wellbeing. The next discussion highlighted the kinds of teacher wellbeing revealed from the trajectories presented in the Activity Theory framework.

\section{Intellectual Wellbeing}

The two junior teachers mentioned that the English course helped them to be better teach- 
er. They found that they were improving through basic and advance trainings organized by the owner director of the English course. Participant 2 who had been working for two years related her motivation, training programs and her intellectual wellbeing.

My motivation to apply for a job here is I really want to be better educator. My friends and my boyfriend told me that this is a good opportunity. I can learn and work and earn money at the same time. In the first 3 months, I got trainings from Ms.X (the owner director). Trainings help me to enhance my knowledge and skills. [Participant 2, Interview]

On the other hand, participant 1 felt satisfied with the training provided by her institution so that she had been able to improve her content knowledge and skill in English.

I realize that at the first time I came here, my English and my teaching skills were fair, but it hadn't met the English course standard, especially my pronunciation. Now I feel I am improving because I had passed the basic trainings. [Participant 1 , Interview]

Participant 6 informed her English ability before and after she was mentored in the training.

I think that I learned nothing when I was pursuing my undergraduate degree. When I came here for the first time, I learned a lot. I could pronounce words correctly. Some of my former lecturers, such as Mr.H, you know; his pronunciation didn't sound English. I've got better pronunciation through the drills my mentor has done to shape my English accurate pronunciation. [Participant 6, Interview]

Three of the subjects mentioned that they improved their knowledge and skills through teacher trainings they underwent in the English course. Positive attitude was showed when they were talking about the trainings that made them good teachers. Their statements represented intellectual wellbeing in which they felt emotional state towards their improvement in the workplace (Holmes, 2005). The institution filled the needs of the teachers by equipping the teachers with fundamental pedagogical skills and content knowledge of English language. This training helped the teachers to be and to feel more ready to play their role as educators and learning facilitators in the class. This finding showed that the role of development trainings held by the institution helped the English teachers to achieve their intellectual wellbeing.

\section{Emotional Wellbeing}

Other two subjects told that the current workplace had a great deal of workload. When they feel too much of their workload, they started to think about resignation. However, thinking about resignation did not come to their real resignation. It was only a situational and changing feeling that triggered them to think of resignation. When they reflected of what the institution had given to them during their career, they felt that they had been in the right place as they felt emotionally well.

I wanted to apply for scholarship abroad and pursued my masters' degree abroad. I am not thinking about it now but may be in the future. I am growing here and I find that it's now my time for keep learning and earning here. My colleagues always support me whenever I have a trouble. I feel this bond and I feel their care. [Participant 5, Interview]

Participant 3 expressed her feeling:

There is sometimes a moment of thinking of resignation, but I always consider and reflect the good things that I might not get in other workplace. [Participant 3, interview]

Resignation can become action that workers take when they feel that they fail to achieve particular wellbeing. It closely relates to emotion in which they feel they can do more that they are doing currently. What participant 5 and participant 3 stated implied their ability to recognize, understand, and express emotions (Holmes, 2005). The recognized their emotion when thinking about resignation and they understand what made them think so. However, they could handle their emotion to stay motivated (Goleman, 1995). Despite their consideration of resignation, Senior 3 and Senior 1 obtained emotional wellbeing that became one of four possible factors influencing overall teachers' wellbeing (Cumming, 2016). Supports from the family and colleagues, and reflections of the positive things the teachers get in the institution potentially strengthen their emotional wellbeing.

\section{Spiritual Wellbeing}

Participant 1 explained about the challenges she met in the classroom. She liked teaching teenagers a as they were easier to handle. However, in this semester she had to deal with students in elementary levels 1-3.

I sometimes feel...not angry, but burdened in class when I have to teach a particular group. To be honest, I am not good at handling children. They are still easy to get distracted with something else. I am the teacher. I have to be able to handle them. I must practice. I don't mention it hard, I mention it challenging. I have to find method to get back their attention, for example with 
games. Children like games, right? [Participant 1 , Interview]

The challenge that participant 1 faced in teaching elementary level sometimes made a burden for her. She realized her capacity and interest of teaching levels. Yet she could set up her spirit of teaching by telling herself that what happened in class was challenge; and she believed in herself that she was able to handle it. Moreover, she also told that her peers were always helpful whenever she asked for their opinion about her teaching strategy plan. Her peers' help played an important role for her to get back her spirit despite the challenges. Participant 1 showed what Holmes (2005) stated about spiritual wellbeing in which she could find source of inspiration to help her work enthusiastically.

On the other hand, participants 5 and 3 represented the relationship with colleagues. Their close relationship was not only limited to the workplace. They often went out together on the weekends or after work to have fun. They also became sharing partners for interests and hobbies besides becoming working partners. In the workplace, participants 5 and 3 also worked together in handling some classes. They always met each other to discuss teaching strategies and students' progress. Moreover, they stated that when one of them could not finish a particular administrative task, such as inputting students' score in the grade record book due to over-workload as a manager, class advisor, and teacher, the other one, who played role as a teacher and class advisor, gave a hand to finish it. Schreyer and Krause (2016) stated that relationship among colleagues has association with job satisfaction. Job satisfaction further could influence the teachers' wellbeing.

Participant 1, moreover, implied that she gained her teacher autonomy while working together in a project with her peer who was her senior.

I felt honored when my director partner me with Ms. T who was my senior to do a project together. Ms. T guided me, but she let me explore my ideas and gave suggestion to develop the raw ideas. She appreciated and always encouraged me so that I felt motivated. [Participant 1, Interview]

Teacher autonomy, however, is needed by every teacher because it influences job satisfaction (Van der Ploeg and Scholte, 2003). Job satisfaction, furthermore, leads to teachers' wellbeing (Cumming, 2016) as it gives spirit for the teachers to feel powerful and confident to do their tasks based on the division of labor.

From the overall discussion, it can be claimed that wellbeing is a complex concept constructed with various variables, such as job satisfaction (Kinman, Wray, \& Strange, 2011), career security, motivation, salary, ability to handle classes, and relationship with colleagues and students (Jennings \& Greenberg, 2009). Those variables are correlated each other. Job satisfaction, which comes when they are able to deal with their division of labour, potentially affects teachers' motivation in dealing with their tasks and their relation to the students. Their ability to handle classes can also affect their motivation to teach. Besides, career security and salary which the institution offers through the rules and divisions of labour cannot be separated from teachers' wellbeing. Once teachers feel satisfied with their salary and job position as seen in the division of labour, they potentially stay in this profession in a particular place.

However, one single variable actually cannot easily make teachers achieve wellbeing. For example, teachers might feel satisfied with the salary they get but they probably do not enjoy the atmosphere at the workplace because of bad relationship with colleagues or students. In this state, teachers fail to achieve wellbeing psychologically. Therefore, emotional and spiritual wellbeing becomes the concern in the context of this study. Through the relationship bonding as one of the wellbeing trajectories in the learning community as seen in the Activity Theory, teachers achieve the wellbeing.

Moreover, it is important to restate the role of teacher wellbeing in the EFL learning community. When the EFL teachers achieve their wellbeing, they will happily develop their creativity to perform teaching and learning activities in class. Their performances in class also affect the students whether they enjoy their learning process with the teachers. While the learning process goes enjoyably, teachers and students will achieve their learning objective. In contrast, teachers and students who do not enjoy the learning process will hardly achieve their learning goals. The depiction of situation shows that teacher wellbeing has been connected to positive students' learning outcomes (Baumeister, Campbell, Krueger, \& Vohs, 2003). It has also been confirmed that positive teacher-student relationship is valuable for learning process and behaviour. Teachers' relationship in a workplace influences their wellbeing and ability to deal with varied stresses which are broadly known teacher profession assertions (Roffey, 2012). 


\section{CONCLUSION}

The findings and discussion of this research shows that the non-formal teachers' wellbeing is constructed with different trajectories. The teachers construct their wellbeing through processes during their professional development. Intellectual wellbeing of the teachers is obtained through trainings organized by the English course as their workplace. Their emotional wellbeing is constructed by the process of reflecting on what they need currently and sharing what they feel towards others. Teachers' spiritual wellbeing is built through the process of self-motivating that make teachers believe in themselves that they are able to do their responsibilities. Hence, it can be concluded that all aspects in the Activity Theory are related each other to contribute to wellbeing being achievement of the non-formal EFL teachers.

This research is based on self-reported data in which potentially desirability bias occurs. The researcher has conducted methodological triangulation in order to minimize the methodological issue. However, further investigation is needed to get more reliable data; frequent on-the-spot observation is recommended to do. This frequent observation could not be done for this present study due to permission. As the discussion of this study is limited to the specific findings of kinds of wellbeing, further study is still needed to find more factors or trajectories constructing teachers' wellbeing. There is also a need to investigate the correlation of EFL teacher wellbeing with the students' English ability development. Future researchers are also expected to do similar research on this topic with different approaches, such as with quantitative approach in order to get the general picture of non-formal English teacher wellbeing.

\section{REFERENCES}

Ary, D., Jacobs, L. C., \& Sorensen, C. K. (2010). Introduction to Research in Education (8th ed.). Wadswoth: Cengage Learning. Retrieved from https://books.google.co.id/ books?id=FqF7n0zGJm0C.

Baumeister, R. F., Campbell, J. D., Krueger, J. I., \& Vohs, K. D. (2003). Does high self-esteem cause better performance, interpersonal success, happiness, or healthier lifestyles? Psychological Science in the Public Interest, 4(1), $1-44$.

Bower, J. M., \& Carroll, A. (2017). Capturing realtime emotional states and triggers for teachers through the teacher wellbeing web-based application: A pilot study. Teaching and Teacher Education, 65, 183-191. https://doi. org/10.1016/j.tate.2017.03.015.

Cassidy, D. J., King, E. K., Wang, Y. C., Lower, J. K., Kintner-duffy, V. L., Cassidy, D. J., ... Lower, J. K. (2016). Teacher work environments are toddler learning environments : teacher professional well-being, classroom emotional support, and toddlers ' emotional expressions and behaviours and toddlers' emotional expressions and behaviours, 4430(June). https://doi.org/10.1080/03004430.2016.11805 16.

Center for Educational Assessment, T. T. (2015). Overview of Education System: Indonesia. Retrieved from http://timssandpirls.bc.edu/ timss2015/encyclopedia/countries/indonesia/

Creswell, J. W. (2012). Qualitative Inquiry and Research Design: Choosing Among Five Approaches. Thousand Oaks: SAGE Publications. Retrieved from https://books.google.co.id/ books?id=OJYEbDtkxq8C.

Cumming, T. (2016). Early Childhood Educators ' Well-Being : An Updated Review of the Literature. Early Childhood Education Journal, (2014). https://doi.org/10.1007/s10643-0160818-6.

Engels, N., Aelterman, A., Petegem, K. Van, \& Schepens, A. (2004). Factors which influence the well-being of pupils in Flemish secondary schools. Educational Studies, 30(2), 127-143.

Engeström, Y. (1999). Activity theory and individual and social transformation. Perspectives on Activity Theory, 19(38).

Engeström, Y., Miettinen, R., \& Punamäki, R.-L. (1999). Perspectives on activity theory. Cambridge university press.

Fantilli, R. D., \& McDougall, D. E. (2009). A study of novice teachers: Challenges and supports in the first years. Teaching and Teacher Education, 25(6), 814-825.

Faulkner, M., Gerstenblatt, P., Lee, A., Vallejo, V., \& Travis, D. (2016). Childcare providers: Work stress and personal well-being. Journal of Early Childhood Research, 14(3), 280-293.

Goleman, D. (1995). Emotional intelligence. New York, NY, England. Bantam Books, Inc.

Holmes, E. (2005). Teacher well-being: Looking after yourself and your career in the classroom. Routledge.

Jennings, P. A., \& Greenberg, M. T. (2009). The prosocial classroom: Teacher social and emotional competence in relation to student and classroom outcomes. Review of Educational Research, 79(1), 491-525.

Kinman, G., Wray, S., \& Strange, C. (2011). Emotional labour, burnout and job satisfaction in UK teachers: The role of workplace social support. Educational Psychology, 31(7), 843-856. https://doi.org/10.1080/01443410.2011.60865 0 . 
Nasional, D. P. (2005). Peraturan Pemerintah Nomor 19 Tahun 2005. Tentang Standar Nasional Pendidikan.

Nislin, M. A., Sajaniemi, N. K., Sims, M., Suhonen, E., Maldonado Montero, E. F., Hirvonen, A., \& Hyttinen, S. (2016). Pedagogical work, stress regulation and work-related well-being among early childhood professionals in integrated special day-care groups. European Journal of Special Needs Education, 31(1), 27-43.

Retallick, J., \& Butt, R. (2004). Professional wellbeing and learning: A study of teacher-peer workplace relationships. Journal of Educational Enquiry, 5(1), 85-99.

Roffey, S. (2012). Pupil wellbeing - Teacher wellbeing : Two sides of the same coin ?, 29(4).
Schreyer, I., \& Krause, M. (2016). Pedagogical staff in children's day care centres in Germany-links between working conditions, job satisfaction, commitment and work-related stress. Early Years, 36(2), 132-147.

van Petegem, K., Creemers, B. P. M., Rossel, Y., \& Aelterman, A. (2005). Relationships Between Teacher Characteristics, Interpersonal Teacher Behaviour and Teacher Wellbeing, 40(2), 34-43.

Veldman, I., van Tartwijk, J., Brekelmans, M., \& Wubbels, T. (2013). Job satisfaction and teacher-student relationships across the teaching career: Four case studies. Teaching and Teacher Education, 32, 55-65. https://doi.org/10.1016/j. tate.2013.01.005. 